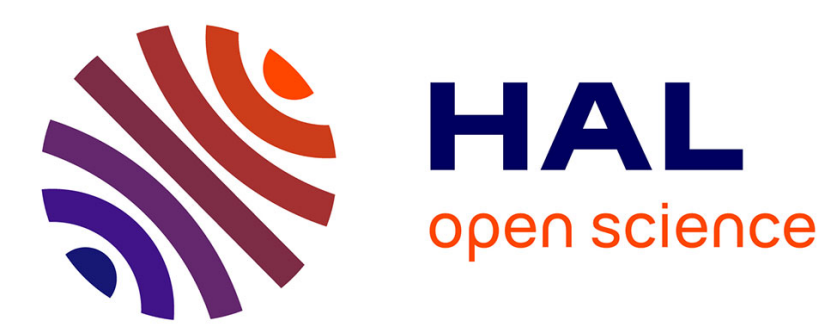

\title{
Nonparametric and semiparametric evidence on the long-run effects of inflation on growth
}

\author{
Andrea Vaona, Stefano Schiavo
}

\section{To cite this version:}

Andrea Vaona, Stefano Schiavo. Nonparametric and semiparametric evidence on the long-run effects of inflation on growth. 2006. hal-01065641

HAL Id: hal-01065641

https://hal-sciencespo.archives-ouvertes.fr/hal-01065641

Preprint submitted on 18 Sep 2014

HAL is a multi-disciplinary open access archive for the deposit and dissemination of scientific research documents, whether they are published or not. The documents may come from teaching and research institutions in France or abroad, or from public or private research centers.
L'archive ouverte pluridisciplinaire HAL, est destinée au dépôt et à la diffusion de documents scientifiques de niveau recherche, publiés ou non, émanant des établissements d'enseignement et de recherche français ou étrangers, des laboratoires publics ou privés. 


\section{The Kiel Institute for the World Economy \\ Duesternbrooker Weg 120 \\ 24105 Kiel (Germany)}

Kiel Working Paper No. 1286

\section{Nonparametric and Semi-parametric Evidence on the Long-Run Effects of Inflation on Growth}

by

Andrea Vaona and Stefano Schiavo

July 2006

The responsibility for the contents of the working papers rests with the authors, not the Institute. Since working papers are of a preliminary nature, it may be useful to contact the authors of a particular working paper about results or caveats before referring to, or quoting, a paper. Any comments on working papers should be sent directly to the authors. 


\title{
Nonparametric and Semiparametric Evidence on the Long-Run Effects of Inflation on Growth *
}

\author{
A. Vaona ${ }^{\dagger}$ and S. Schiavo ${ }^{\ddagger}$
}

\begin{abstract}
In this paper we adopt both a nonparametric and a semiparametric IV estimator to show that the relationship between inflation and output growth is non-linear and that there exists a threshold level below which inflation has no effects on growth.

Jel codes: E31, O49, C14.

Keywords: Inflation, Growth.

${ }^{*}$ The authors would like to thank Fabrizio Carmignani, Francesco Daveri, Abdelhak Senhadji and an anonymous referee for their helpful comments. The usual

${ }^{\dagger}$ Corresponding author. The Kiel Institute for the World Economy and University of Verona, Department of Economic Sciences, Polo Zanotto, Viale dell'Università 4, 37129, Verona, Italy. Tel.: (+39)0458028102. E-mail: an-

${ }_{\ddagger}^{\ddagger}$ Department of Computer and Management Sciences, University of Trento, Via Inama 4, 38100 Trento. E-mail: sschiavo@economia.unitn.it, phone: (+39)0461882115, fax: $(+39) 0461882124$.
\end{abstract} disclaimer applies. drea.vaona@economia.univr.it 


\section{Aim of the Paper and Literature Review}

The aim of this paper is to reassess by means of both a nonparametric estimator and a semiparametric instrumental variable (IV) estimator the issue of the long-run relationship between inflation and economic growth.

The existing empirical literature uses spline models in the belief that a threshold level of inflation exists below which increasing inflation fosters output growth and above which more inflation hampers it. However, first, the theoretical literature had considerable difficulties in matching this stylized fact (Temple, 2000) and, second, different empirical contributions have assumed different threshold levels without being able to test their assumptions (with the exception of Khan and Senhadji, 2001). For instance Fischer (1993) imposes a spline model with two breaks, one at $15 \%$ annual inflation rate and the other at $40 \%$. Gylfason and Herbertsson (2001) find that the relationship between inflation and growth is non-linear and the threshold inflation rate to be around 10\%. Ghosh and Phillips (1998) assume the kink of the spline to be at 2.5\%, whereas Judson and Orphanides (1999) choose 10\%.

A threshold effect is found also by Thirlwall and Barton (1971) at an annual inflation rate ranging from $8 \%$ to $10 \%$. A similar value is suggested also by Sarel (1996). One notable contribution is Khan and Senhadji (2001) who find the threshold to be around 1\% for industrialized countries and $11 \%$ for developing ones. However, the result for the industrialized countries is not completely convincing because the number of observations for which inflation is below $1 \%$ is rather small and in most cases they represent rare and temporary occurrences with little chance to impact on long-term growth. Hence, the paucity of observations, together with the assumption of the spline model, may drive the result.

In order to take better care of these issues, we think that nonparametric and semiparametric estimators allow to let as much as possible the data speak shedding further light on both the threshold level of inflation and its non-linear relationship with output growth. Furthermore, by adopting a semiparametric IV estimator it is possible to tackle the issue of the endogeneity of inflation, a problem that most of the above contributions neglect.

\section{Model Specification and Data Issues}

We focus on two model specifications both of which builds on Khan and Senhadji (2001). The dependent variable is the growth rate of GDP in constant local currency units. In Specification I controls include the level of inflation, gross fixed capital formation (or gross capital formation 
when the former is not available) as a share of GDP, the log of initial per capita GDP in PPP adjusted dollars, population growth, a measure of education and the share of government expenditures over GDP. In addition, robustness checks are performed controlling for inflation volatility and financial development. In Specification II, the growth rate of the terms of trade and their 5-year standard deviation are also included. Inflation is instrumented by its first $\operatorname{lag}^{1}$.

Data come from different sources: whenever possible we refer to the World Bank's World Development Indicators (WDI). For per capita GDP and the share of government consumption we revert to Penn World Tables (PWT), while our education measure (average schooling years in the total population aged 15 or more) comes from the Barro and Lee dataset on educational attainment. Terms of trade data are built from export and import unit value series taken from the IMF's International Financial Statistics (IFS), while financial development indicators are taken from Beck et al. (2000).

The dataset covers the period 1960-1999, which is the maximum length common to all data sources, and 167 countries. Terms of trade data are available for a smaller set of (mainly developed) countries and they are therefore not included in our baseline specification, but only used as a robustness check.

As customary when focusing on long-term growth (Temple 2000), we divide all series into 8 equal periods of 5 years each and we consider 5 -years means (or medians), although we experiment with different frequencies as well.

The actual number of available observations is reduced due to the presence of missing data, especially for developing countries (whose IFS code is 200 or above). Moreover, we drop from the sample all observations for which the rate of inflation is above $40 \%$ : the semiparametric estimator is extremely sensitive to outliers, therefore we adopt the leave-one-out estimator (Pagan and Ullah, 1999) which brings us to trim observations for which inflation is above a certain threshold. We are not the first to recognize this problem: Temple (2000) warns against the risk of pooling together countries with very different inflation dynamics, as few extremely high values may well drive the overall results. The $40 \%$ cutoff point is also employed in Khan and Senhadji (2001), while Gillman et al. (2004) show that using different truncation points generates negligible differences in the results.

In the end our sample contains 85 countries and 421 observations, 119 of which pertain to 19 industrial countries. Adding the terms of

\footnotetext{
${ }^{1}$ Results about the validity of the instrument are available from the authors upon request.
} 
trade variables substantially reduces the sample size: while developed countries are almost unaffected, the number of developing countries in the sample falls from 66 to 25 .

\section{Estimation Method, Results and Conclusions}

A nonparametric estimator is one of the tools that it is possible to use when the relationship between two variables is thought to be non-linear. Furthermore, in order to control for the effect of other covariates, it is possible to use a semiparametric estimator. In this contribution, we follow Park (2003) and we implement a semiparametric IV estimator that accounts for the potential endogeneity of inflation.

The main assumption of Park (2003) is that in the following model

$$
y_{i}=x_{1 i}^{\prime} \beta+\phi\left(x_{2 i}\right)+u_{i}
$$

$E\left[u_{i} \mid x_{2 i}\right]$ is not null, where $y$ is the dependent variable, $x_{j i}$ for $j=1,2$ are two sets of independent variables, $\phi(\cdot)$ is a non-linear function of unspecified form and $i$ is the subscript for the i-th observation.

Let $z_{i}$ be the set of instrumental variables: one first filters out the exogenous part of $\phi\left(x_{2 i}\right)$ by computing $g\left(z_{1 i}\right)=E\left[\phi\left(x_{2 i}\right) \mid z_{1 i}\right]$ and then obtains the model:

$$
y_{i}=x_{1 i}^{\prime} \beta+g\left(z_{1 i}\right)+v_{i}
$$

where $E\left[v_{i} \mid z_{1 i}\right]=0$. At this stage, supposing $x_{1 i}$ to be exogenous, following Robinson (1988) it is possible to obtain estimates of beta as follows:

$$
\hat{\beta}=\left[\sum_{i=1}^{n}\left(x_{1 i}-\hat{m}_{12 i}\right)\left(x_{1 i}-\hat{m}_{12 i}\right)^{\prime}\right]^{-1}\left[\sum_{i=1}^{n}\left(x_{1 i}-\hat{m}_{12 i}\right)\left(y_{i}-\hat{m}_{2 i}\right)^{\prime}\right]
$$

where $\hat{m}_{12 i}$ and $\hat{m}_{2 i}$ are the non-parametric estimators of $m_{12 i}=E\left(x_{1 i} \mid z_{i}\right)$ and $m_{2 i}=E\left(y_{i} \mid z_{i}\right)$. More in detail, the nonparametric estimator of $m_{2}$ is:

$$
\hat{m}_{2}=\frac{\sum_{i=1}^{n} K\left(\frac{z_{i}-z}{h}\right) y_{i}}{\sum_{i=1}^{n} K\left(\frac{z_{i}-z}{h}\right)}
$$

where $h$ is the bandwidth and $K(\cdot)$ is the kernel function. Once having $\hat{\beta}$ in hand it is easy to find $\hat{g}\left(z_{i}\right)$ :

$$
\hat{g}\left(z_{i}\right)=\hat{m}_{2 i}-\hat{m}_{12 i} \hat{\beta}
$$

In this contribution, we use a Gaussian kernel and Silverman's optimal bandwidth (Pagan and Ullah, 1999). 
Table 1 shows the parameter estimates for the control variables. Figure 1 shows the result for a nonparametric estimation of the relationship between inflation and real GDP growth: the threshold inflation level is around 12 percent. Below it inflation does not appear to be particularly harmful to growth, while above it their relationship becomes markedly negative and steeper. Figure 2 shows the results for the semiparametric IV estimator. The continuous line traces $\hat{g}\left(z_{i}\right)$, whereas the dotted lines mark the $95 \%$ confidence interval. Overall, inflation does not appear to affect growth in a substantial way. The first box of Figure 3 shows that the same result would appear using 5 years medians instead of 5 years means, as suggested by Temple (2000). However, splitting the sample between developed and developing countries, as usual in the literature above (Khan and Senhadji, 2001), provides fruitful insights. The threshold level sticks to around $12 \%$ for developed countries, whereas no clear cut result emerges for the group of developing ones. This is probably the results of the very different experiences undergone by the economies grouped under this label: the relationship between inflation and growth goes up and down for different inflation levels. Adding terms of trade data (Specification II) does not alter the results in any significant way. Similarly, results are robust to the introduction of inflation volatility and different measures of financial development among control variables ${ }^{2}$.

The last exercise implemented in the paper deals with the frequency of the data. One aspect of the growth-inflation nexus that standard regression analysis has addressed poorly concerns the possibility that the relationship varies by frequency. While we find no major change for developing countries, an interesting effect appears for the group of industrialized economies. Figure 4 shows that moving from 3 to 5 to 8 years averages lets a positive relationship between inflation and real growth emerge at low inflation levels. In particular, as displayed in the right panel of Figure 4, below $4 \%$ inflation exerts a positive effect on long-run growth, while the relationship becomes markedly negative for rates above $5-6 \%$

This paper uses a nonparametric estimator and a semiparametric IV one to assess the issue of the non-linear relationship between inflation and economic growth and the existence of a threshold effect within it. Our results point to the fact that inflation does not have a substantial effect on economic growth when it is below $12 \%$ in developed countries and that the high variability of growth performances in developing countries does not allow to find a precise threshold level for inflation. Moving

\footnotetext{
${ }^{2}$ In particular, liquid liabilities to GDP, deposit money bank assets to GDP, and private credit by deposit money banks to GDP. These results are not displayed and are available from the authors upon request.
} 
from 3 to 5 to 8 years averages lets a positive relationship between inflation and economic growth emerge that turns negative above $5-6 \%$. Whilst we do not address the issue of the allocative inefficency generated by inflation, our results also suggest that - from the standpoint of its impact on growth - the importance of low inflation targeting may have been overstated. However, it is also confirmed that high inflation is detrimental to economic growth.

\section{References}

[1] Beck, T., Demirgüç-Kunt, A. and Levine, R. (2000), "A New Database on Financial Development and Structure", World Bank Economic Review, 14, 597-605.

[2] Fischer, S. (1993), "The Role of Macroeconomic Factors in Growth", Journal of Monetary Economics, 41, 485-512.

[3] Ghosh, A. and Phillips, S. (1998), "Inflation, Disinflation and Growth", IMF Working Paper, WP/98/68.

[4] Gillman, M., Harris M. N., and Matyas, L. (2004), "Inflation and Growth: Explaining a Negative Effect", Empirical Economics, 29, $149-167$.

[5] Gylfason, T. and Herbertsson, T. (2001), "Does Inflation Matter for Growth?", Japan and the World Economy, 13(4), 405 - 428.

[6] Judson, R. and Orphanides, A. (1999), "Inflation, Volatility and Growth", International Finance, 2(1), 117-138.

[7] Khan, S. and Senhadji, A. (2001), "Threshold Effects in the Relationship Between Inflation and Growth", IMF Staff Papers, 48 (1), $1-21$.

[8] Park, S. (2003), "Semiparametric Instrumental Variable Estimation", Journal of Econometrics, 112, 381 - 399.

[9] Pagan, A. and Ullah, A. (1999), Nonparametric Econometrics, Cambridge University Press.

[10] Robinson, P. (1988), "Root-N-consistent Semiparametric Regression", Econometrica, 56, 931 - 954.

[11] Sarel, M., (1996), "Nonlinear Effects of Inflation on Economic Growth", IMF Staff Papers 43, 199-215.

[12] Temple, J. (2000), "Inflation and Growth: Stories Short and Tall", Journal of Economic Surveys, 14 (4), 395-426.

[13] Thirlwall, A. P. and Barton, C. A. (1971), "Inflation and Growth: The International Evidence", Banca Nazionale del Lavoro Quarterly Review 98, 263-275. 
Table 1 - Coefficient estimates of the control variables

\begin{tabular}{cccccccc}
\hline \hline & \multicolumn{9}{c}{ Specification I } & & \multicolumn{3}{c}{ Specification II } \\
& All & Developed & Developing & Median & All & Developed & Developing \\
\hline \hline GDP per cap. & $-4.40^{*}$ & $-6.02^{*}$ & $-4.26^{*}$ & $-4.01^{*}$ & $-6.53^{*}$ & $-5.66^{*}$ & $-5.93^{*}$ \\
t-statistics & $(-7.49)$ & $(-4.56)$ & $(-6.18)$ & $(-6.47)$ & $(-6.92)$ & $(-4.00)$ & $(-4.30)$ \\
Pop. growth & $1.53^{*}$ & 0.02 & $1.73^{*}$ & 0.25 & 0.35 & 0.56 & 0.47 \\
t-statistics & $(9.13)$ & $(0.05)$ & $(8.63)$ & $(0.84)$ & $(1.03)$ & $(1.17)$ & $(0.87)$ \\
Investment/GDP & $0.18^{*}$ & $0.16^{*}$ & $0.21^{*}$ & $0.14^{*}$ & $0.28^{*}$ & 0.11 & $0.37^{*}$ \\
t-statistics & $(7.06)$ & $(2.64)$ & $(6.34)$ & $(5.56)$ & $(7.35)$ & $(1.59)$ & $(5.55)$ \\
Gov.Consumption & -0.05 & $-0.10^{*}$ & -0.02 & $-0.09^{*}$ & -0.06 & $-0.12^{*}$ & -0.01 \\
t-statistics & $(-1.77)$ & $(-2.88)$ & $(-0.52)$ & $-3.35)$ & $(-1.62)$ & $(-2.95)$ & $(-0.11)$ \\
Education & 0.10 & 0.37 & 0.01 & 0.08 & 0.23 & 0.41 & 0.22 \\
t-statistics & $(0.54)$ & $(1.81)$ & $(-0.03)$ & $(0.38)$ & $(0.93)$ & $(1.76)$ & $(0.41)$ \\
T. of Trade Growth & - & - & - & - & $0.07 *$ & $0.11^{*}$ & 0.07 \\
t-statistics & - & - & - & - & $(2.08)$ & $(2.30)$ & $(1.23)$ \\
T. of Trade Stan. Dev. & - & - & - & - & 0.78 & -6.43 & 0.86 \\
t-statistics & - & - & - & - & $(1.90)$ & $(-1.66)$ & $(1.43)$ \\
\hline \hline
\end{tabular}

*: significant at the $5 \%$ level

Figure 1 - Non-parametric estimation of the effect of inflation on real economic growth

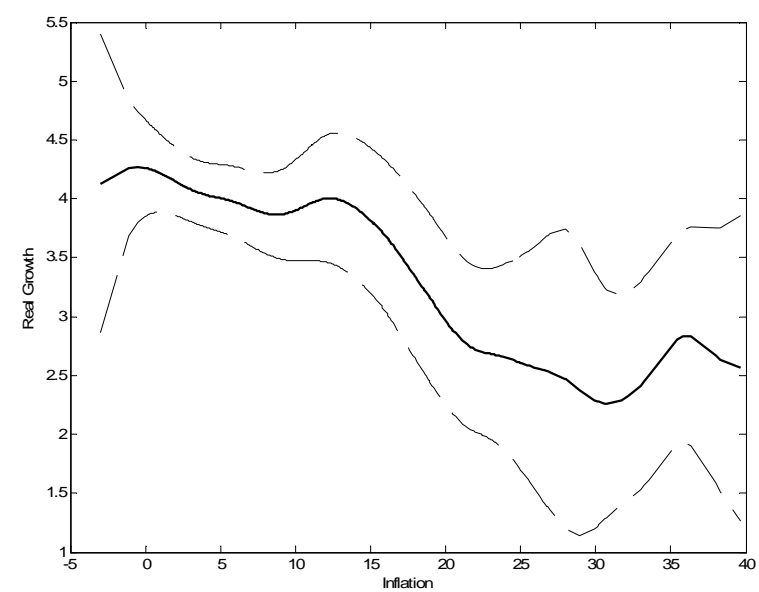

Figure 2 - Semi-parametric IV estimation of the effect of inflation on real economic growth

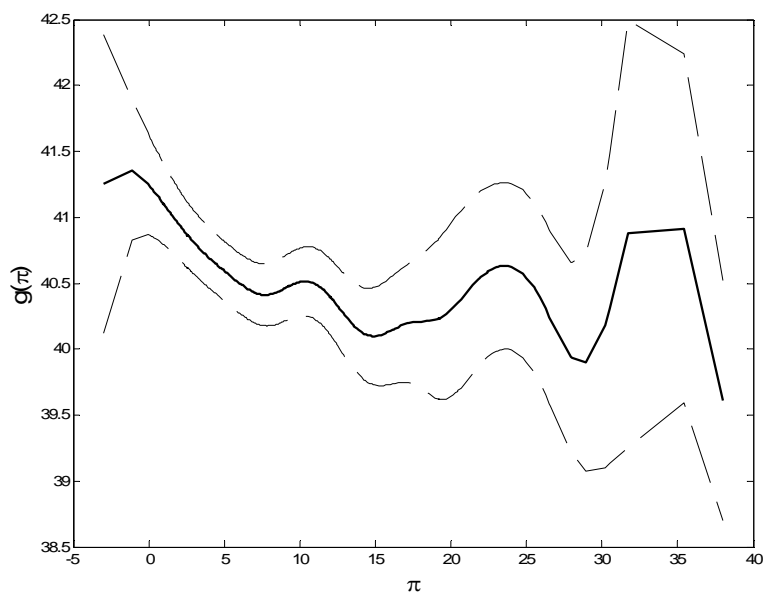


Figure 3 - Robustness checks for the Semiparametric IV estimation of the effect of inflation on real economic growth

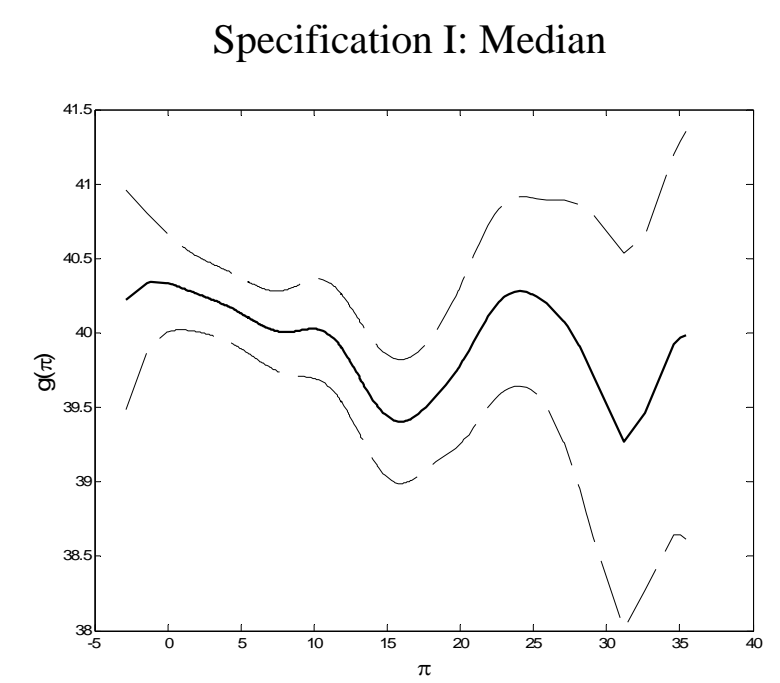

Specification II: entire sample

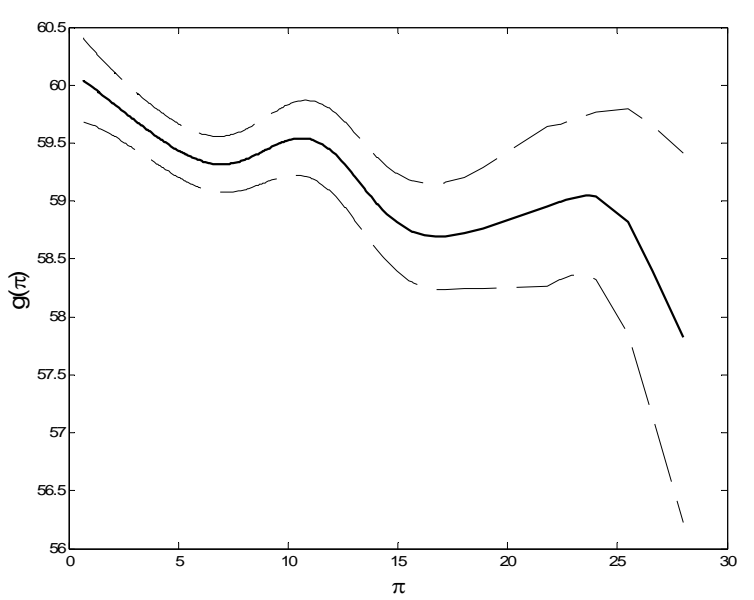

Specification I: Developed Countries

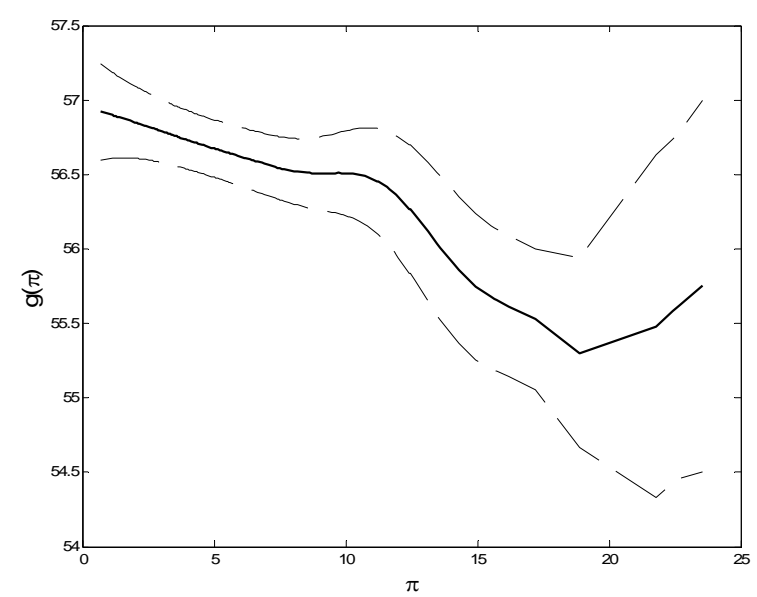

Specification II: Developed Countries

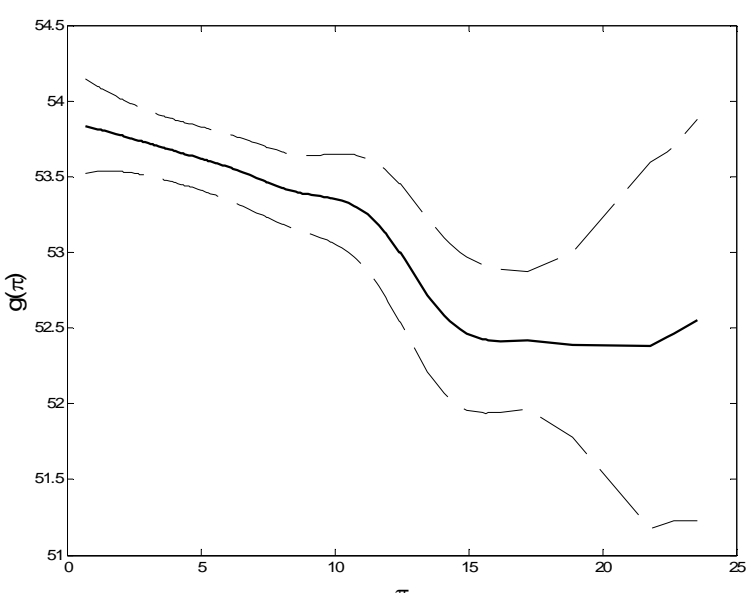

Specification I: Developing countries

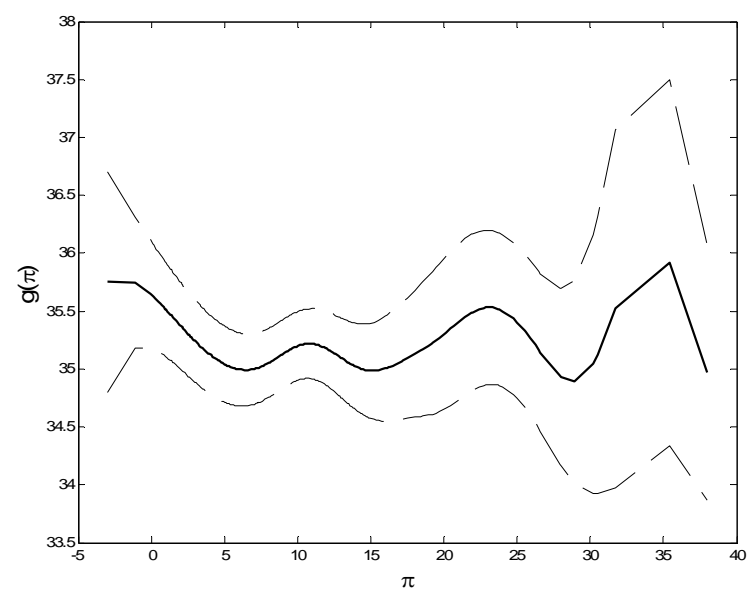

Specification II: Developing Countries

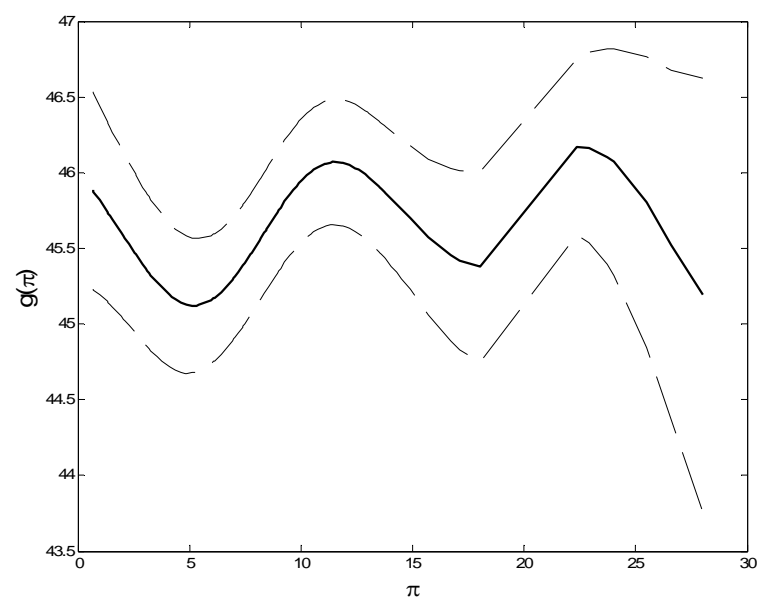


Figure 4 - The effect of inflation on real economic growth in developed countries at different frequencies (Semiparametric IV Estimator)

3 Years Averages

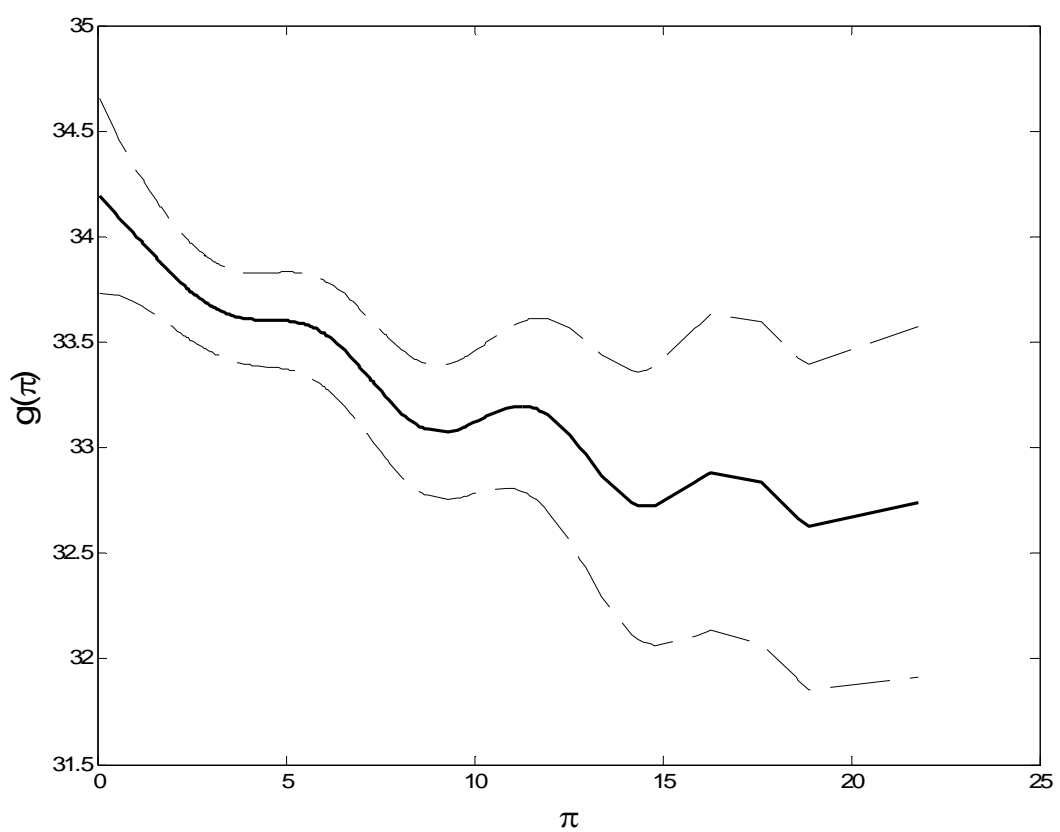

8 Years Averages

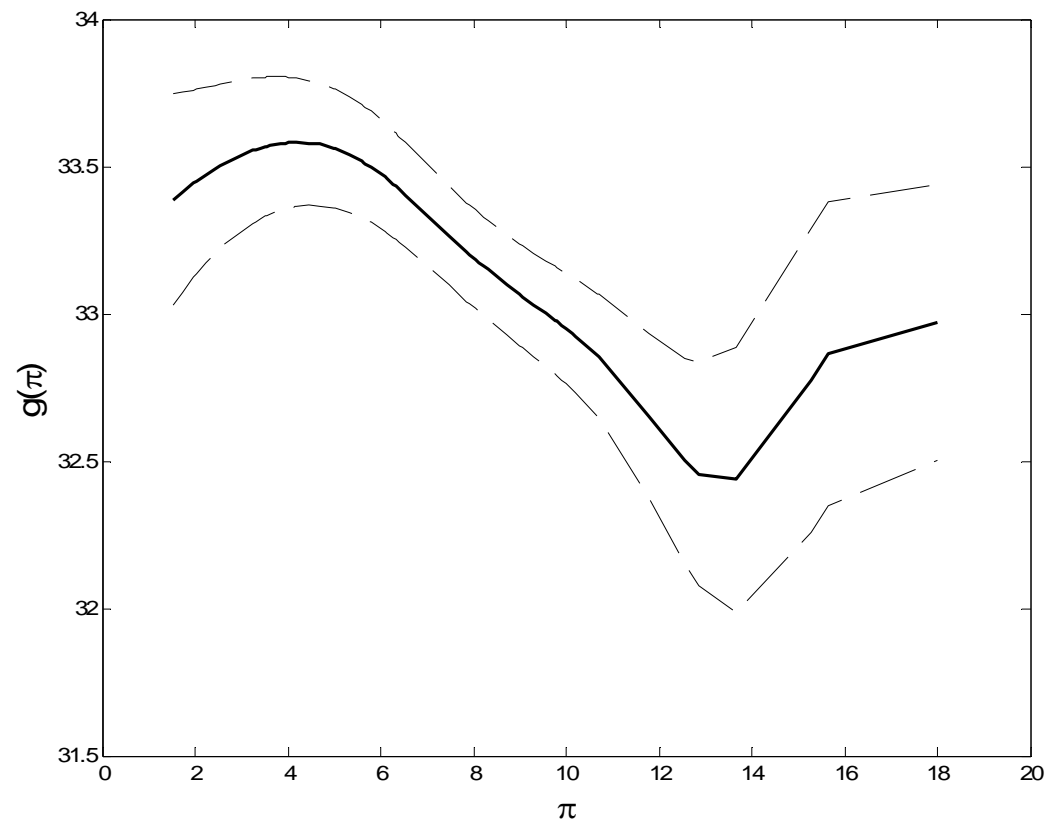

